\title{
Sulfated DHEA Measurement
}

National Cancer Institute

\section{Source}

National Cancer Institute. Sulfated DHEA Measurement. NCI Thesaurus. Code C96629.

The determination of the amount of sulfated dehydroepiandrosterone (DHEA) present in a sample. 